\title{
A STUDY OF SOME FORMS OF CONTINUITY FOR MULTIFUNCTIONS IN IDEAL TOPOLOGICAL SPACES
}

\author{
CHAWALIT BOONPOK
}

\begin{abstract}
The main goal of this article is to introduce the concepts of $\star(\alpha)$ continuous multifunctions and almost $\star(\alpha)$-continuous multifunctions. Some characterizations of $\star(\alpha)$-continuous multifunctions and almost $\star(\alpha)$-continuous multifunctions are established. Furthermore, the relationships between $\star(\alpha)$ continuity and almost $\star(\alpha)$-continuity are discussed.
\end{abstract}

MSC 2010. 54C08, 54C10, 54C60.

Key words. $\alpha$ - $\mathscr{I}^{\star}$-open set, $\star(\alpha)$-continuous multifunction, almost $\star(\alpha)$-continuous multifunction.

\section{REFERENCES}

[1] M.E. Abd El-Monsef, E.F. Lashien and A.A. Nasef, On $\mathscr{I}$-open sets and $\mathscr{I}$-continuous functions, Kyungpook Math. J., 32 (1992), 21-30.

[2] A. Açikgöz, Ş. Yüksel and E. Gursel, On a new concept of functions in ideal topological spaces, Journal of Faculty of Science, Ege University, 29 (2006), 30-35.

[3] A. Açikgöz, T. Noiri and Ş. Yüksel, On $\alpha-\mathscr{I}$ - continuous and $\alpha-\mathscr{I}$-open functions, Acta Math. Hungar., 105 (2004), 27-37.

[4] C. Berge, Espaces topologiques fonctions multivoques, Dunod, Paris, 1959.

[5] C. Boonpok, On some types of continuity for multifunctions in ideal topological spaces, Advances in Mathematics: Scientific Journal, 9 (2020), 859-886.

[6] C. Boonpok, Weak quasi continuity for multifunctions in ideal topological spaces, Advances in Mathematics: Scientific Journal, 9 (2020), 339-355.

[7] C. Boonpok, On continuous multifunctions in ideal topological spaces, Lobachevskii J. Math., 40 (2019), 24-35.

[8] E. Hatir, A. Keskin and T. Noiri, A note on strong $\beta-\mathscr{I}$-open sets and strongly $\beta-\mathscr{I}$ continuous functions, Acta Math. Hungar., 108 (2005), 87-94.

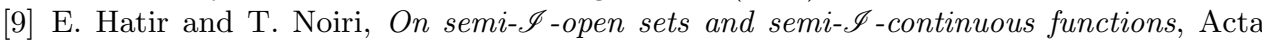
Math. Hungar., 107 (2005), 345-353.

[10] E. Hatir and T. Noiri, On decompositions of continuity via idealization, Acta Math. Hungar., 96 (2002), 341-349.

[11] D. Janković and T.R. Hamlett, New topologies from old via ideals, Amer. Math. Monthly, 97 (1990), 295-310.

[12] K. Kuratowski, Topology, Volume I, Academic Press, New York, 1966.

[13] A.S. Mashhour, I.A. Hasanein and S.N. El-Deeb, $\alpha$-continuous and $\alpha$-open mapping, Acta Math. Hungar., 41 (1983), 213-218.

This research project was financially supported by Mahasarakham University.

DOI: $10.24193 /$ mathcluj.2021.2.05 
[14] O. Njåstad, On some classes of nearly open sets, Pacific J. Math., 15 (1965), 961-670.

[15] T. Neubrunn, Strongly quasi-continuous multivalued mapping, in General Topology and its Relations to Modern Analysis and Algebra VI (Prague 1986), Heldermann, Berlin, 1988, pp. 351-359.

[16] T. Noiri, On $\alpha$-continuous functions, Časopis Pro Pěstování Matematiky, 109 (1984), $118-126$

[17] T. Noiri, Almost $\alpha$-continuous functions, Kyungpook Math. J., 28 (1988), 71-77.

[18] V. Popa and T. Noiri, On upper and lower almost $\alpha$-continuous multifunctions, Demonstratio Math., 24 (1996), 381-396.

[19] V. Popa and T. Noiri, On upper and lower $\alpha$-continuous multifunctions, Math. Slovaca, 43 (1993), 477-491.

[20] V. Vaidyanathswamy, The localization theory in set topology, Proc. Indian Acad. Sci., 20 (1945), 51-61.

Received October 30, 2019

Mahasarakham University

Accepted February 12, 2021 Mathematics and Applied Mathematics Research Unit Department of Mathematics, Faculty of Science Maha Sarakham, 44150, Thailand

E-mail: chawalit.b@msu.ac.th

https://orcid.org/0000-0002-4094-727X 